Res Mobilis Revista internacional de investigación en mobiliario

y objetos decorativos

Vol. $5, n^{\circ} .6$ (I), 2016

\title{
EL MUEBLE DE LOS SIGLOS XVI Y XVII EN CUBA 16th and 17th CENTURIES CUBAN FURNITURE
}

\author{
Lilia Martín Brito* \\ Universidad de Cienfuegos, Cuba.
}

\section{Resumen}

El panorama del mueble cubano de los siglos XVI y XVII es un tema poco conocido. El desarrollo socioeconómico de la Isla en esos siglos no permitió notables muestras. Si las hubo, la mayoría no se ha conservado. Durante la empresa colonizadora el parco ajuar de que se acompañaron los conquistadores trajo consigo los aires del Renacimiento. Con el avance de los siglos XVI y XVII, los muebles recibieron la influencia del Barroco español con cierta timidez. Del siglo XVII se conservan camas, armarios, sillas y sillones fraileros. Probablemente un tipo de mueble muy popular en Cuba a lo largo de su historia, haya surgido en este siglo, el conocido como taburete cubano. A pesar de su escasez, los ejemplares conservados, permiten acercarse a un mundo casi ignorado que posibilita reconstruir el inicio de un proceso sumamente importante en la historia del arte cubano y en particular de sus muebles.

Palabras clave: Mobiliario, Renacimiento, Barroco, costumbres, maderas preciosas.

\section{Abstract}

The panorama of the Cuban furniture of the 16 and 17th centuries is a not very well-known topic. The socioeconomic development of the Island in those centuries didn't allow notables examples. If there were, the most has not been conserved. During the colonize epoch-the scanty trousseau that the conquerors accompanied he/she brought with them the airs of the Rebirth. With the advance of the XVI and XVII centuries, the furniture received the influence of the Spanish Baroque with certain shyness. Of the XVII century beds, cupboard, seats and "monks" arm chairs are conserved. Probably a type of very popular piece of furniture in Cuba along of-their history, be-emerged in this century, the wellknow as Cuban stool. In spite of their shortage, the conserved copies, they allow to come closer to an almost unknown world that permits to reconstruct the beginning of an extremely important process in the history of the Cuban art and in particular of their furniture.

Keywords: Furniture, Rebirth Baroque customs, beautiful wood.

\footnotetext{
*E-mail: 1martin@ucf.edu.cu
} 


\section{Introducción.}

El tema del mueble cubano fue escasamente estudiado en el pasado siglo $\mathrm{XX}$. Los diferentes autores que lo trataron, con enfoques distintos unas veces, y coincidentes otras, ${ }^{1}$ tuvieron un punto de concurrencia, ninguno trató de explicarse el porqué de la calidad del mueble cubano en las diferentes épocas. Mientras algunos no sobrepasaban una somera periodización, referida a la descripción de las características más generales del mobiliario cubano, otros, han reconocido su belleza y aportan valoraciones en cuanto a su desarrollo en Cuba. Caso aparte constituyen los juicios de Francisco Prat Puig quien supo apreciar la valía del mueble cubano y descubrió singularidades, cuyas incógnitas, no alcanzó a despejar del todo, pero dejó suficientes alertas en cuanto a los valores de la cultura material cubana en general y del mueble cubano en particular. Aunque apenas publicó al respecto, queda como testimonio de sus criterios más relevantes sobre el tema, una entrevista publicada en $1985^{2}$.

Todo ello conduce a la elaboración de una hipótesis que gira en torno al siguiente planteamiento: El mueble de los siglos XVI y XVII en Cuba se confecciona mayoritariamente en el país. Su principal valor radica en las maderas preciosas cubanas con que se elabora desde un inicio. Al carácter austero de los mismos en el siglo XVI, se suma la presencia, en algunos casos, de las hermosas tallas que dicha madera posibilita en los finales del siglo XVII, favorecidas además, por la presencia en Cuba de carpinteros de ribera desde la decimosexta centuria. Ambos elementos confieren al mueble cubano cierta peculiaridad que lo va diferenciando del resto del mueble Iberoamericano desde muy temprano.

Por tanto los objetivos de este trabajo se relacionan con: Explicar que el uso de maderas cubanas de alta calidad y la insistencia en los documentos en cuanto a su uso, es factor distintivo del mueble cubano desde los inicios de su historia. Reconocer el valor del mueble cubano desde fechas tempranas. Evidenciar la presencia de carpinteros de ribera en Cuba desde el siglo XVI, lo cual posibilita la construcción de muebles de calidad a partir del siguiente siglo.

El proceso de investigación está conformado por un alto componente heurístico, donde el protagonismo de las fuentes primarias, constituidas por los propios muebles, con el apoyo de métodos de tipo teóricos como el Histórico-lógico y el de Historia comparada. Los de tipo empírico, como la Observación científica, y técnicas como las entrevistas a expertos, ha posibilitado una valoración acertada del mobiliario de esta época en Cuba, con el apoyo de materiales integrados por dichos muebles, ubicados en su casi totalidad en museos cubanos, y los documentos, constituidos mayoritariamente por testamentos e inventarios, así como bibliografía especializada y fotografías. 


\section{Desarrollo}

El mueble en Cuba, sin lugar a dudas, puede ser colocado entre las producciones más dignas de su cultura material. ${ }^{3}$ En los siglos XVI, XVII, la precaria economía de Cuba, no dejó espacio para un gran desarrollo del mueble, tanto de tipo doméstico como en el orden religioso.Si a ello se suma que en la Europa de la época los muebles no fueron muy abundantes, se podrá entender que en la empresa colonizadora de los primeros años, muy pocos trajeron consigo los españoles. El parco ajuar de que se acompañaron los conquistadores, trajo consigo los aires del Renacimiento, inclusive mucho antes de que este llegara a la modesta arquitectura de los años iníciales. El mismo sirvió para suplir las más perentorias necesidades.

Las descripciones existentes acerca del mobiliario del siglo XVI en Cuba son exiguas, por lo tanto, las muestras de muebles que se conservan de este siglo, son muy escasas y se reducen a muebles españoles que debieron llegar a Cuba en etapas más tardías por la vía del coleccionismo. Las arcas o cajones que han llegado hasta la actualidad, por su tipología transitan hasta el siglo XVII sin cambios aparentes, tanto por las técnicas empleadas como por sus elementos decorativos. Estos trasvasan hacia un tímido barroco, sobre todo en lo herrajes, estilo que sólo a finales de siglo XVII alcanza en algún armario y cierta cajoneras, sus mejores expresiones.

Las condiciones establecidas por el uso de las abundantes maderas preciosas cubanas, así como el sobrio tratamiento de las mismas, cuya nobleza, alivió desde los primeros años la ausencia de tallas y taraceas o marqueterías, ${ }^{4}$ tan en boga en el mueble europeo y muy especialmente en España a través de más de tres siglos, propiciarían las diferencias entre el mueble traído por los colonizadores y el confeccionado en Cuba. El empleo del cedro y la caoba "de la tierra" dieron al mueble cubano posibilidades inusitadas que permiten reconocer valores identificables en estos, desde los primeros siglos.

\section{El mueble del siglo XVI en Cuba}

En la primera mitad del siglo XVI en Cuba, los muebles de algún valor, además de constituir rarezas, fueron traídos por los colonizadores. Aquellos muebles más ricos debieron tener, como ya se dijo, elementos decorativos, con influencia del Renacimiento italiano como sucedía sobre todo en el norte de Europa, ${ }^{5}$ pero a su vez, el Renacimiento en España, recibe por un lado, la fuerte presencia de elementos árabes y por otro, los resabios góticos que allí se prolongaron en el tiempo. ${ }^{6}$ Ello otorga al mueble hispano una fisonomía muy peculiar de gran sabor, por su casticismo, entre ellos las sillas de brazos o sillones, conocidos como "fraileros", 7 y escritorios que más tardíamente comenzarían a denominarse bargueños. ${ }^{8}$

En la España del siglo XVI el mobiliario era escaso y pesado dentro de los palacios, y en la mayoría de los casos, movible y práctico, ${ }^{9}$ para aquella trashumante nobleza que influenciada por la larga y reciente guerra de 
reconquista, se había acostumbrado al traslado de casi todo su ajuar de un lugar a otro. De alguna forma, ciertas piezas equivalentes a este tipo de muebles, debieron llegar a Cuba. Por lo que los muebles de la primera mitad del siglo XVI introducidos en la incipiente colonia, no debieron diferenciarse mucho de los que se usaban en la península ibérica.

La explotación temprana de las maderas cubanas en las más disímiles funciones, permite imaginar su empleo en la confección de muebles de variado tipo, lo que convierte en certero horizonte la siguiente afirmación de Francisco Prat Puig:

\begin{abstract}
"Se sospecha que los muebles usados en los primeros siglos de la colonia fueron muy pobres y escasos tanto en variedad como en construcción, pero hay que pensar, en fin, que desde el principio, el hombre radicado o nacido en nuestra Isla se esforzó en labrarse sus rumbos de desarrollo en medio de la aspereza ambiental, y que pudo hacerse de sillas, sillones, mesas, arcones, taburetes, escabeles, bancos y otros mobiliarios; unos rudimentarios, otros más o menos elegantes y todos sólidos y de recio sabor hispano - renacentista."10
\end{abstract}

El permiso concedido por los reyes para la construcción de embarcaciones en la isla de Fernandina, luego Cuba, datado en diciembre de 1516, ${ }^{11}$ indica que algunos colonos dominaban el oficio de carpintero de ribera, por lo que no debe extrañar la posibilidad de confección de algunos muebles de cierta calidad desde los inicio. Dicha tarea se mantuvo a través del tiempo y sin ser una industria reconocida, no dejó de realizarse, hasta alcanzar calidad notable en las producciones de los siglos posteriores.

Las primeras referencias a muebles en los documentos más antiguos se remontan a 1525, durante el Juicio de Residencia realizado al Adelantado Diego Velázquez por el Juez de Residencia y Gobernador Licenciado Juan Altamirano. Entre las providencias tomadas

“...mandó notificar á los regidores de desta dicha cibdad( Bayamo)que compren o faganfacer dos arcas, la una para tener en la cárcel pública desta dicha cibdad, e la otra para las escripturas del cabildo." ${ }^{2}$ En las preguntas realizadas a los testigos en dicho juicio, no se indaga por arcas sino por cajas “...en que se guardan los dichos procesos para questén á recabdo, e si han tenido libro de todos los procesos que han tenido, e venido á la cárcel (...)". ${ }^{13}$

Los muebles no eran prioridad en estos años, ni siquiera en Europa, no obstante, en algunos casos, se tornaban imprescindibles y era necesario importarlos. Su aparición en los listados de mercancías es mucho menos frecuente que los géneros y las telas, estos últimos no contaban con algún tipo de alternativa para su confección en Cuba, como si lo tenían los muebles. El arancel 
que se cobraba en 1552 en la carga y descarga de buques "Por una cama de colchón y frasada (sic) y almohada de un hombre" era de un real. "y si fuere de dos colchones" importaba dos reales. ${ }^{14}$

Una de las formas de vida de La Habana, fue el alquiler de habitaciones para la población flotante que desde muy temprano se albergó en ella, motivado por La Carrera de Indias. El cabildo de 24 de abril de 1556 estipula el arancel que pagarán ciertas "casas de tratos" que no sólo venden diferentes tipos de alimentos sino que también ofertan un lugar donde comer y/o dormir, por lo que "las tales personas que dieren de comer sean obligadas a dar agua a los que comieren, la que les bastare mesa y manteles limpios, de valde, sin llevar para ello interés alguno. Que si alguna persona quisiese dormir en las tales casas de tratos y se le diere una hamaca, lleven por cada noche un real y si no diesen hamaca ni otra cosa, medio real". ${ }^{15}$ Esa otra "cosa" sugiere un jergón como cierto tipo de comodidad o quizás una cama, como aquellas importadas para "un hombre" en las que pudiera descansar quien estuviera de paso.

En 1561 Francisco de Parada, vecino de Santiago de Cuba, era uno de los hombres más ricos de la colonia. Así, dispone en su testamento que sean vendidas "ciertas haciendas de Bacas(sic) y negros" que posee en Bayamo y entre otros aspectos orienta que con todo lo que se reúna, se erija una capilla en Medina de las Torres, España y "luego se ponga por obra de hacerse, y se haga una Iglesia o Parroquia en la dicha villa de Bayamo (...)"16 Pero, además ,hace referencia a un cofre de tres llaves que contendría el producto de las ventas que se guardaría en la propia Iglesia o Parroquia beneficiada con la donación. Otra descripción de este tipo de mueble y su uso en Cuba aparece en las Ordenanzas del oidor Alonso de Cáceres de $1573 .{ }^{17}$

En las variadas estipulaciones dejadas para el funcionamiento de los cabildos, la consignada con el número 28,refiere: "Quen las casas de dicho cabildo haya un arca donde estén los libros de cédulas y provisiones de S.M. que en este cabildo se presentan, y las escrituras y recaudos de esta villa y las demás cosas que S. M. por sus leyes pragmáticas manda; y otra donde esté el dinero de esta villa y tenga tres llaves, la una tenga uno de los alcaldes, la otra el regidor más antiguo y la otra el escribano."18En ese mismo año de 1573 Gonzalo de Rojas, procurador de la villa de La Habana tenía en su casa una de estas cajas de tres llaves, ${ }^{19}$ lo que indica su uso primario como cajas de seguridad. Las que han llegado hasta hoy, son de una sola cerradura y por tanto tuvieron una sola llave que por lo general no se conserva.

La constante aparición de estas arcas o cajones en testamentos y otros documentos, lleva a pensar en que alguna de las que se conservan actualmente, pertenecieron al siglo XVI, dado que era el mueble más común para guardar la ropa, objetos de valor , alimentos, ${ }^{20}$ además de que se usaban como asientos.

El recibo de promesa de dote que Gonzalo Vaca recibió de Catalina Marqués en 1588 declara "en virtud de los bienes que por dos mil ducados y cinco reales al contado y el resto de unas casas, joyas, muebles, ropas y otros objetos" 21 por su futuro casamiento con María Recia. Entre ellos se encuentran: una tinaja para agua "de las de castilla", dos estrados, un escaño, seis guadamecíes, dos 
colchones una cama de "rred", ${ }^{22}$ dos sábanas de ruán; dos camisas de "Holanda", una saya de paño azul, una "mesa de gonçes con sus pies y cadena"; ${ }^{23}$ tres cajas de cedro, un cofre grande de "flandres"; tres tocadores labrados de oro y plata, "una golguera en de (sic) de encaxes"; un espejo grande de cristal y un paño de mesa, entre otros.

Entre los objetos más notables en este recibo de dote se encuentran los dos estrados: Su pluralidad sugiere que están en uso el estrado llamado de "cumplimiento" y el de "cariño", de los tres que era costumbre poseer y exhibir entre los más poderosos de España y sus colonias ${ }^{24}$. Estos, junto al escaño, que se reconoce en la época como un mueble que es asiento y arca a la vez, ${ }^{25}$ denotan una complejidad en el ajuar que adiciona al conjunto los valores representativos de una dama de abolengo. ${ }^{26}$ Todo ello sumado a los muebles descritos con anterioridad, revela la presencia de costumbres españolas en la segunda mitad del siglo XVI trasladadas a cualquiera de sus colonias en América. Mientras, las connotadas cajas de cedro, se convierte en los primeros objetos identificables como criollos confeccionados en Cuba. Las maderas preciosas autóctonas conque fueron confeccionadas, empiezan a imponer su sello de calidad e identidad. ${ }^{27}$

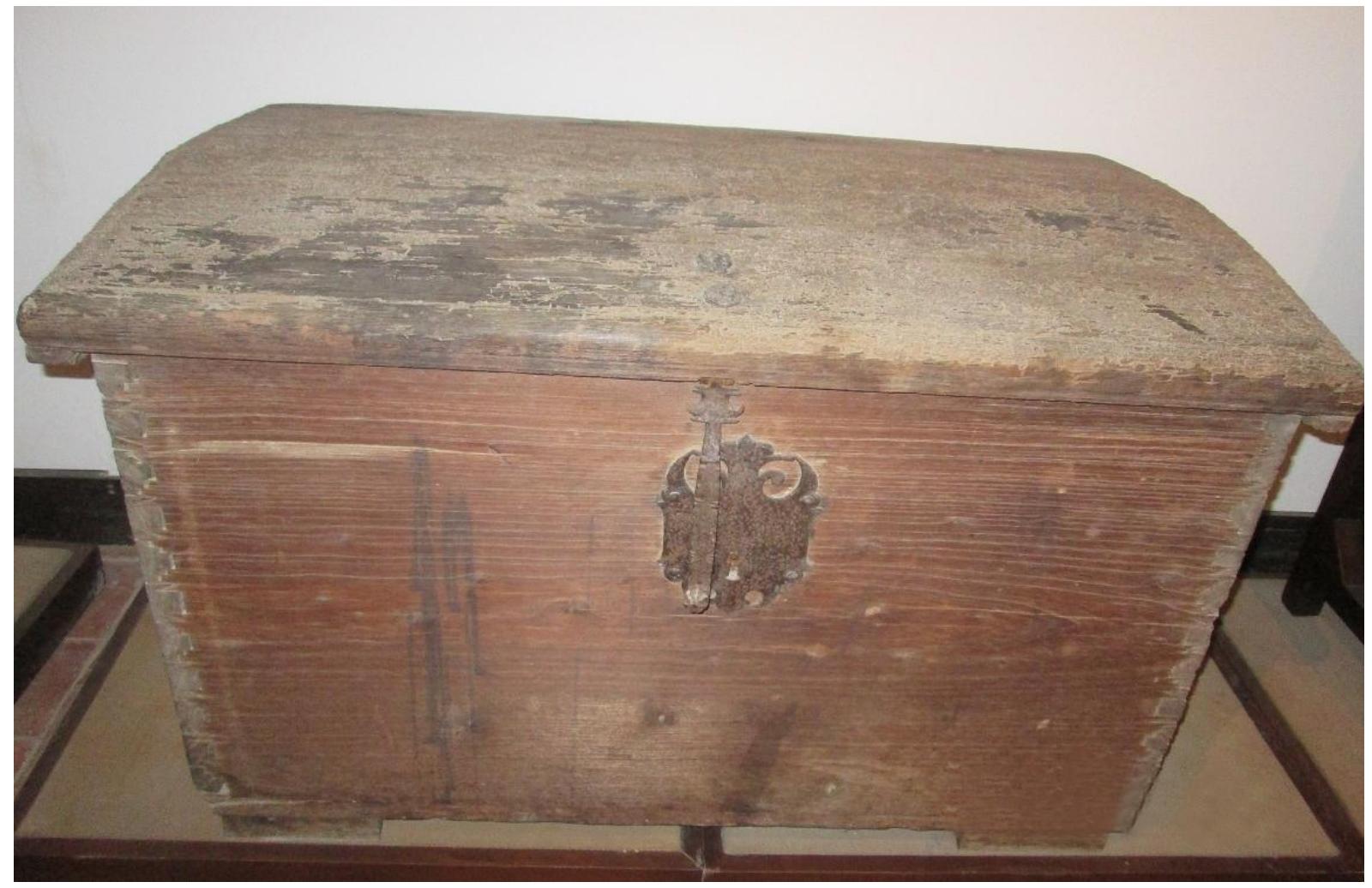

Fig.1. Cajón de cedro de fines del siglo XVI o principios del siglo XVII.Museo de Arte Colonial, La Habana. 
Estas cajas llegaron a poseer un aspecto y significado muy particular en cuanto al resto de América Latina, tanto que en la décimo séptima centuria, eran conocidas en México como "cajas de cedro de la Habana".28 Ya fueran identificadas como cajas, cajones o arcas, también se hicieron de caoba. Las que han llegado hasta nuestros días, poseen características en cuanto a técnicas de ensamblaje y herrajes que permiten ubicarlas entre los finales del siglo XVI e inicios del siglo XVII. (Fig. 1)

En 1593 el inventario por el fallecimiento del capitán Francisco de Moncayo, radicado en La Habana que ostentaba el oficio de veedor y contador de galeras, revela la composición de su mobiliario:“(...) diez sillas de caobana, "un bufete de caobana grande, y otro pequeño de lo mismo", otro bufete pintado, otro bufete de caobana, labrado con hueso blanco, una mesilla de cedro, una caja de cedro que sirve de despensa, dos alfombras, una cama torneada de caoba, "con su armadura y cualga de tafetán colorado", dos almohadas de terciopelo colorado "con los suelos de cuero, viejas", dos colchones de lana, cuatro sábanas, una colcha, un cofre grande viejo, otras dos cajas de cedro, dos baúles con cubiertas de cuero. Completa el conjunto doce lienzos de Flandes "pintados de figuras" y "otro lienzo pintado de la Imagen de Ntra. Señora"29

Entre los muebles catalogados, los bufetes y las sillas de caoba debieron confeccionarse en Cuba, así como los cajones, casi todos de cedro, uno de ellos, se declara como despensa, por lo que la mesa de cedro pudo ser su soporte. Los demás cajones de cedro debieron guardar las cosas de más valor del difunto, para ello servían también los baúles. ${ }^{30}$ La posesión de una cama de caoba torneada, ilustra sobre el alcance del modo de vida en Cuba a fines del siglo XVI. ${ }^{31}$ Otros muebles inventariados son dos "cajones escritorios" y un "escritorio con cajones" que estaban en aposento aparte y formaban parte delo que debió ser su despacho. ${ }^{32}$ Para los mismos no se describen tallas o algo parecido, pero es de suponer que al connotar la presencia de caoba en los variados muebles, se está estableciendo una diferencia, si no por su belleza, al menos se indica la calidad a pesar de lo austeros que estos pudieran resultar.

De este siglo se conservan en Cuba una silla y un escritorio que por la elaboración de su talla, pueden ser atribuidos a la segunda mitad del mismo: La silla tiene varias modificaciones en su asiento, pero exhibe en su espaldar una inscripción en latín que suscribe al parecer alguna conmemoración, en ella se lee: “Anno domini 1527".Lo más interesante de esta talla radica en las dos figuras masculinas de cuerpo entero, con evidente desproporción y el torso desnudo, con una escueta vestimenta que sugiere un taparrabo, todo ello en una interpretación bastante tosca del plateresco ${ }^{33}$. (Fig.2) 
El escritorio incompleto y con varias intervenciones también, es del tipo conocido como "a la italiana" confeccionada en castaño y nogal de franca filiación manierista. Sus tallas, un tanto rústicas, superan en calidad las del mueble anterior. Este ha perdido su parte baja o credencia. En cambio le fueron adicionadas dos patas talladas con la figura de sendos perros, que probablemente fueron los soportes de la desaparecida credencia. ${ }^{34}$ Se desconoce el origen de estos muebles, como ya se dijo, probablemente el coleccionismo fue forma de llegar Cuba, en épocas posteriores. No obstante, por su rareza, ameritan que se siga indagando acerca de ellos, de manera que se pueda en algún momento, demostrar o negar definitivamente su presencia en Cuba desde el siglo XVI. (Fig.3)

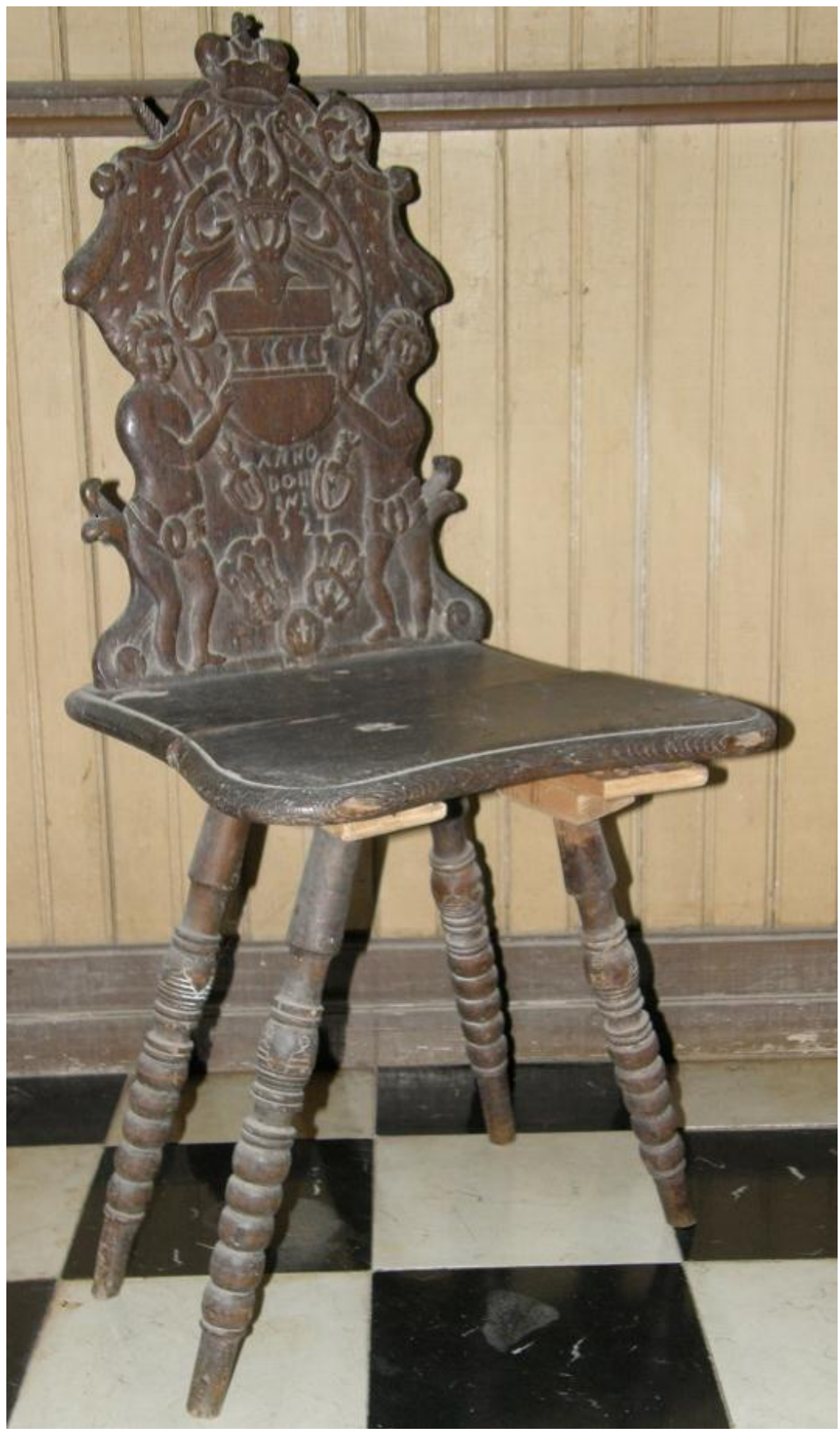

Fig. 2. Silla del siglo XVI. Colección Francisco Prat Puig. Santiago de Cuba. 


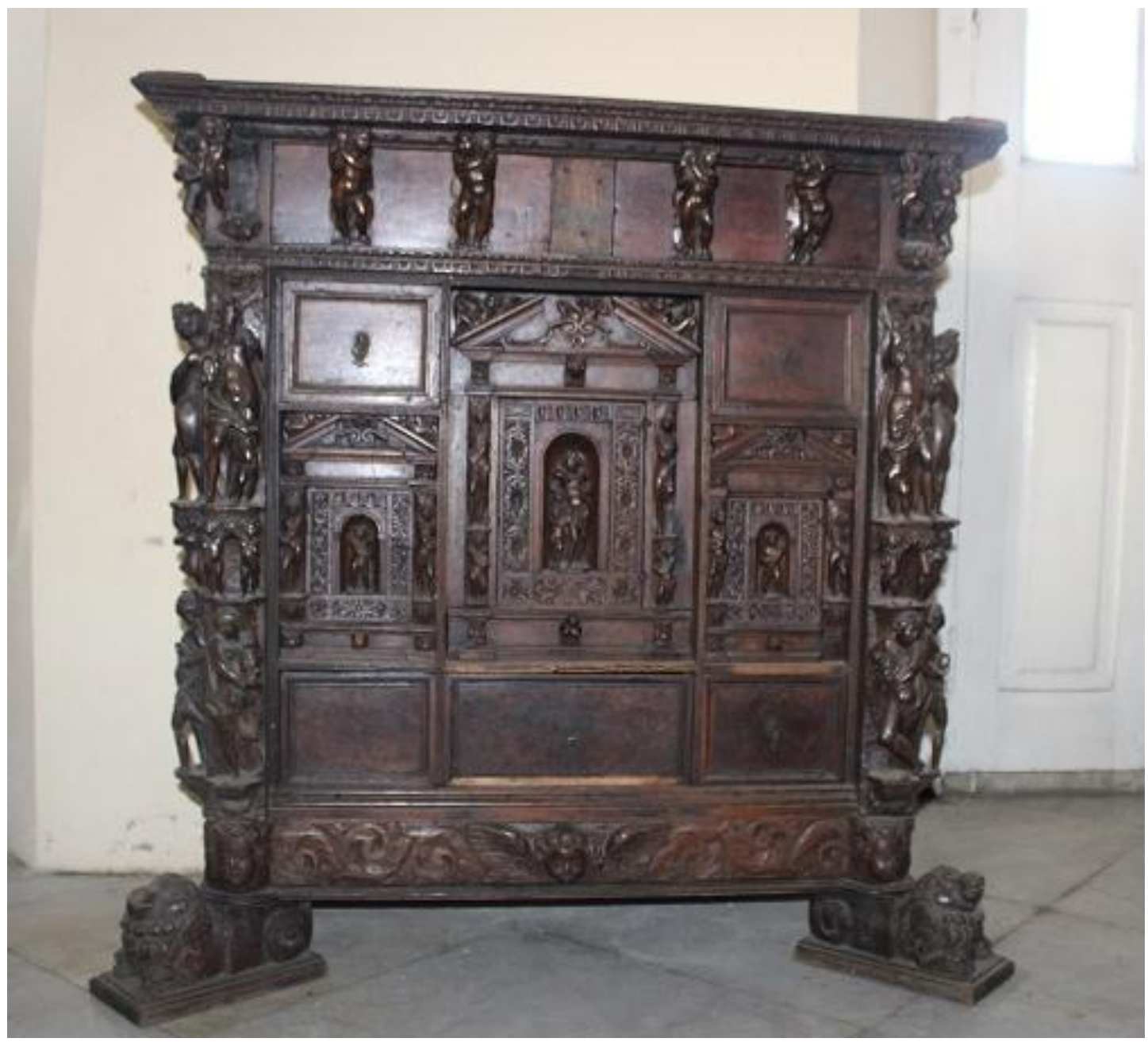

Fig. 3. Escritorio español “a la Italiana” del siglo XVI. Castaño y nogal. Dirección Provincial de Patrimonio Cultural. Cienfuegos.

\section{El mobiliario del siglo XVII en Cuba. Algunas definiciones.}

El tránsito al siglo XVII no es muy diferente a lo sucedido en el anterior. La Habana continuaba con la ayuda que recibía desde el siglo XVI, o sea "los situados" de México para construir las fortalezas que protegerían la Villa. Además, junto a una economía de servicio como forma de vida aleatoria para cierto sector de sus habitantes beneficiado por la población flotante generada por la estancia de las flotas en su puerto, en este siglo la exportación de cueros crudos, constituyó casi el único renglón exportable de importancia, junto al de las maderas preciosas. El resto de las villas tendría como mejor forma de vida el comercio de rescate o contrabando donde el intercambio a través del corso y la piratería jugaron un papel fundamental para su subsistencia.

En el siglo XVII van tomando forma dos nuevas industrias que vendrían a ser la base del comercio exterior cubano en los siglos siguientes: la producción de 
azúcar y el cultivo el tabaco. A estas se sumaron otras dos industrias, que con su altas y bajas "alcanzarían auge inicial y periodos coyunturales favorables", o sea, las construcciones navales y la explotación del cobre. ${ }^{35}$ Todo ello permitió la aparición o consolidación de ciertos capitales y el surgimiento de algunos nuevos apellidos en la conformación de la oligarquía cubana.

Este paulatino desarrollo propició la elaboración de un tipo de mueble, de franca influencia española, en su modalidad más práctica la mayoría de las veces, sin embargo, el uso común del cedro y la caoba, le confiere al mueble realizado en Cuba una apariencia que lo va diferenciando paulatinamente del mobiliario al uso en la península ibérica, comúnmente confeccionado en roble, nogal, pino ${ }^{36}$.

Entre los principales muebles pertenecientes al siglo XVII en Cuba se encuentra un escritorio de gran belleza, correspondiente a la primera mitad de dicho siglo. Como los muebles españoles descritos anteriormente, se desconoce su forma de arribar a Cuba, si perteneció a algún coleccionista o si algún rico hacendado lo encargó a España como mueble de alto significado representativo del poder y linaje. Lo cierto es que el geometrismo de sus tallas en hueso y marfil y la elaborada composición de sus herrajes lo insertan en el más castizo herreriano le imprimen valores agregados a su antigüedad y belleza. (Fig.4)

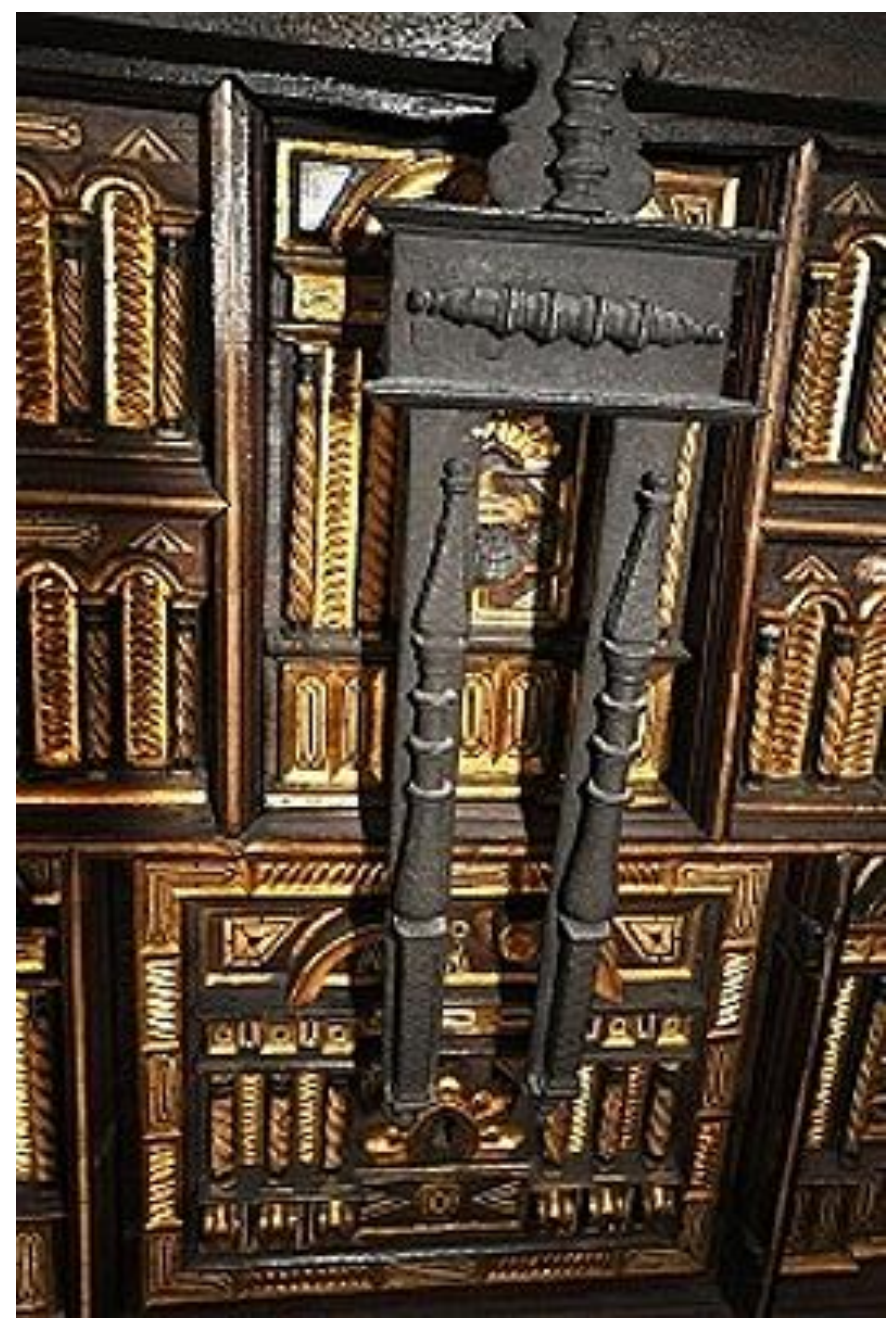

Fig.4. Detalle de un escritorio español del Siglo XVII. De tipo herreriano, realizado en nogal con tallas de hueso y marfil y elaborados herrajes Museo de la Ciudad, La Habana. 
Igualmente se conserva una cajonera escritorio confeccionada en pino, de extrema sencillez en su talla, no obstante, por sus herrajes de bisagras alargadas, bocallave y aldaba ${ }^{37}$ que es posiblemente uno de los pocos muebles de su tipo conservados en Cuba y como tal es muy singular. Posee tres gavetas rectangulares, cuyas agarraderas son de bronce, por su forma ubicables en el siglo XVII. El cajón superior posee una tapa abatible al frente, esta y la aldaba de hierro que le sirve de cierre a uno de sus costados, sitúa a este mueble dentro de las características de dicho siglo en cuanto al mueble español de tipo muy funcional.(Fig.5)

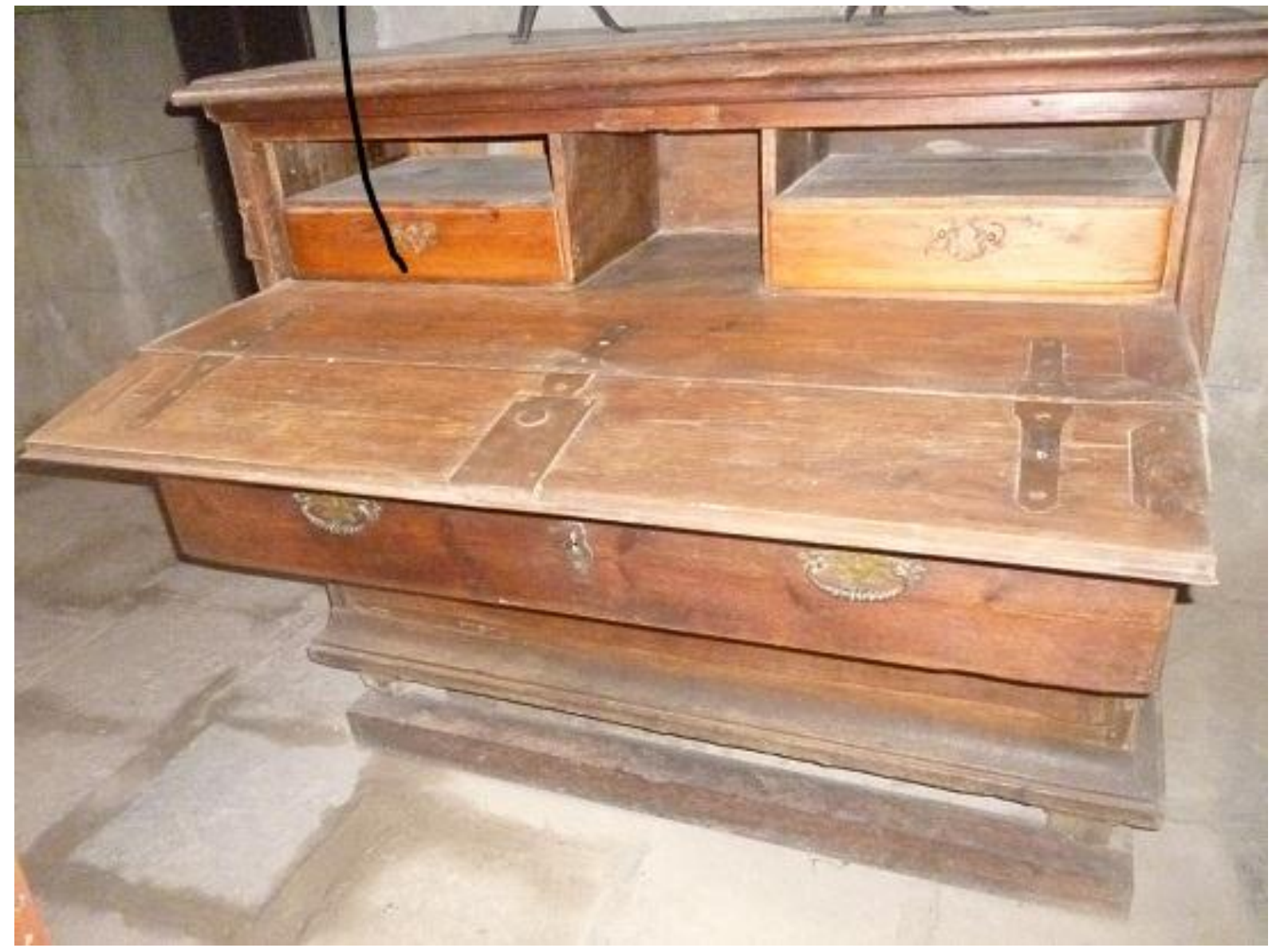

Fig.5. Cajonera escritorio confeccionado en pino con aldaba, bisagras y bocallave de hierro, manijas de los cajones de bronce. Museo de Arte Religioso, Antiguo Convento de San Francisco. La Habana.

Entre los muebles cubanos más antiguos se encuentra un armario de cedro, cuya rusticidad y técnica lo acercan al siglo XVI. Cada una de las dos amplias hojas que lo cierran, poseen seis grandes tableros rectangulares, realizados a partir de largueros y peinazos, ligeramente moldurados, y fijados con clavos de cáncamo, colocados toscamente a vista. De ellos, los cuatro superiores tienen un letrero inciso con la siguiente leyenda: "Armario del Señor de la Humildad". Sus patas delanteras y traseras, son aparentemente rectilíneas, pero por sus lados, 
están unidas entre sí por un tablero recortado con una curvatura que describe un arco conopial. Este elemento y la moldura que decora su interior lo ubican en el siglo XVII. (Fig.6)

Perteneciente al siglo XVII es también un armario decorado con cuarterones en sus dos amplias hojas. Es más ancho que profundo y posee tableros y peinazos rectilíneos, de reducido tamaño que encierran en su interior tallas conformadas indistintamente por figuras a base triángulos, rombos y pequeños rectángulos. La apariencia geométrica de dicho mueble le da una apariencia muy original, con resabios mudéjares, apegados a la interpretación popular española. La madera usada en su confección es cedro, lo que lo ubica como un mueble cubano. (Fig.7)
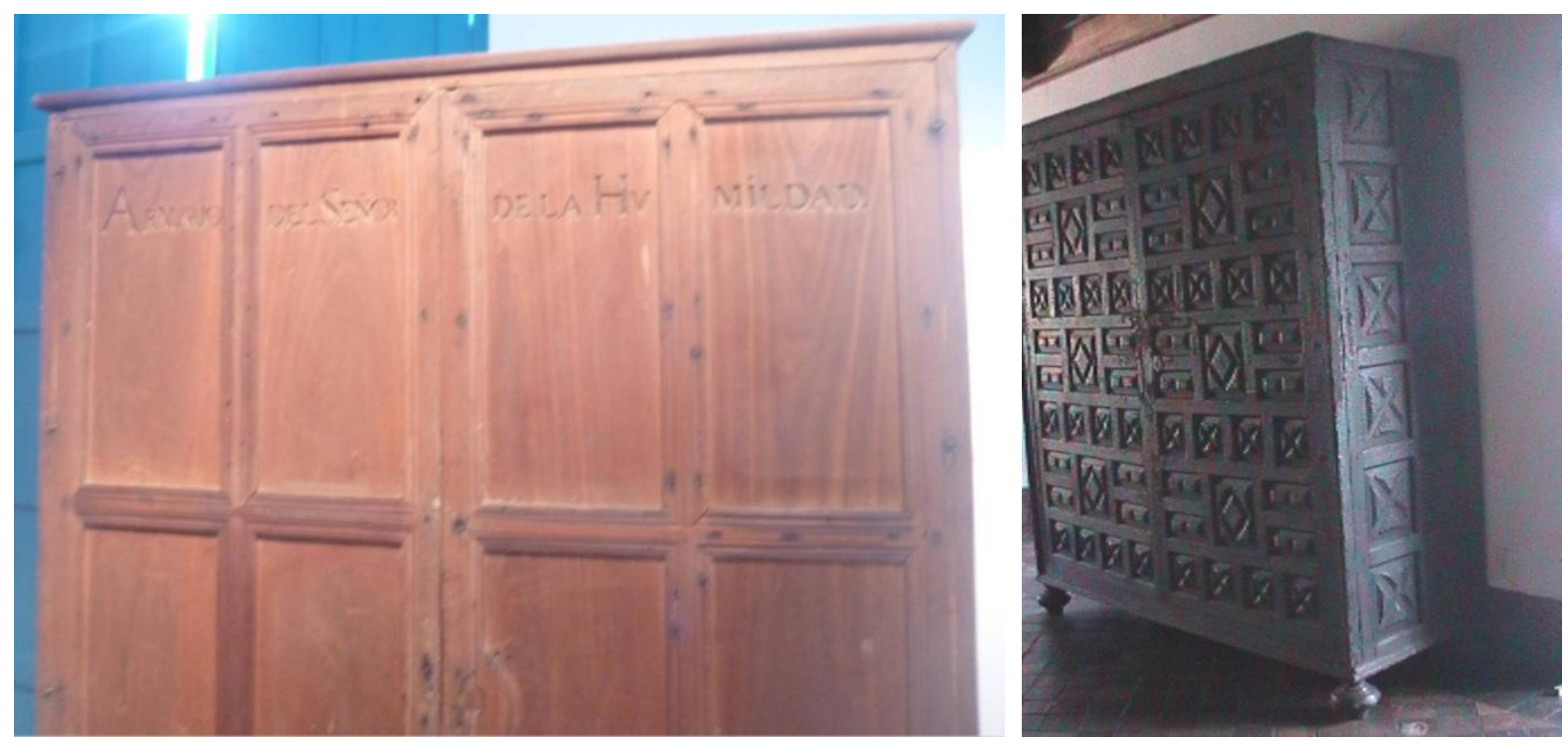

Fig.6. “Armario del señor de la humildad”. Siglo XVII confeccionado en cedro y ensamblado con clavos en forma de presillas. Museo de Arte Colonial, La Habana.

Fig.7. Armario de cuarterones de cedro. Siglo XVII. Museo de Ambiente Histórico de la ciudad de Santiago de Cuba.

Probablemente de la segunda mitad del siglo, es una cama con su cabecero y pies torneados. Acerca de ella se ha expresado: "Recibe el nombre de carretel por el tornerío tan menudo de sus parales y balaustres que se repiten reiteradamente, haciendo gala abusiva del torno, hecha con maderas preciosas cubanas: majagua y baría, con influencia hispana e inspiración morisca." 38 Lo cierto es que uno de los ejemplares más logrados de su tipo en Cuba. (Fig.8)

También del siglo XVII se conservan varios asientos confeccionados en madera, vaqueta y grandes clavos de metal. Resulta difícil la ubicación de estos muebles en el tiempo, dado que su técnica y forma de construcción estuvo vigente por espacio de más de un siglo, sin embargo, la ligera curvatura que decora la parte superior de su espaldar o la recortada ondulación de algunas de sus chambranas los ubica en el tránsito del siglo XVII al XVIII. (Fig.9) El sillón "frailero" o silla de brazos en Cuba ha llegado hasta la actualidad como un 
mueble de uso religioso. A pesar de ser la iglesia, el lugar donde más se les encuentra, no fue privativo de esta, sino de todo aquel que tuvo caudal para poseerla

En las sillas del siglo XVII, está el antecedente del taburete cubano. Los taburetes que generalmente, desde antaño y hasta la actualidad, son especie de banquetas sin espaldar altas o bajas de tres o cuatro patas. Sin embargo, en Cuba, el tipo de asiento denominado taburete aún posee una fisonomía muy parecida a la silla sin brazo española de los siglos XVI y XVII. El taburete en Cuba en el siglo XVII no debió ser diferente a lo acostumbrado en España, debió ser una banqueta mucho más simple, sin ningún tipo de torneado en sus patas y sin acolchado, con el asiento de cuero, dada su abundancia en el país, pero aún sin respaldo.

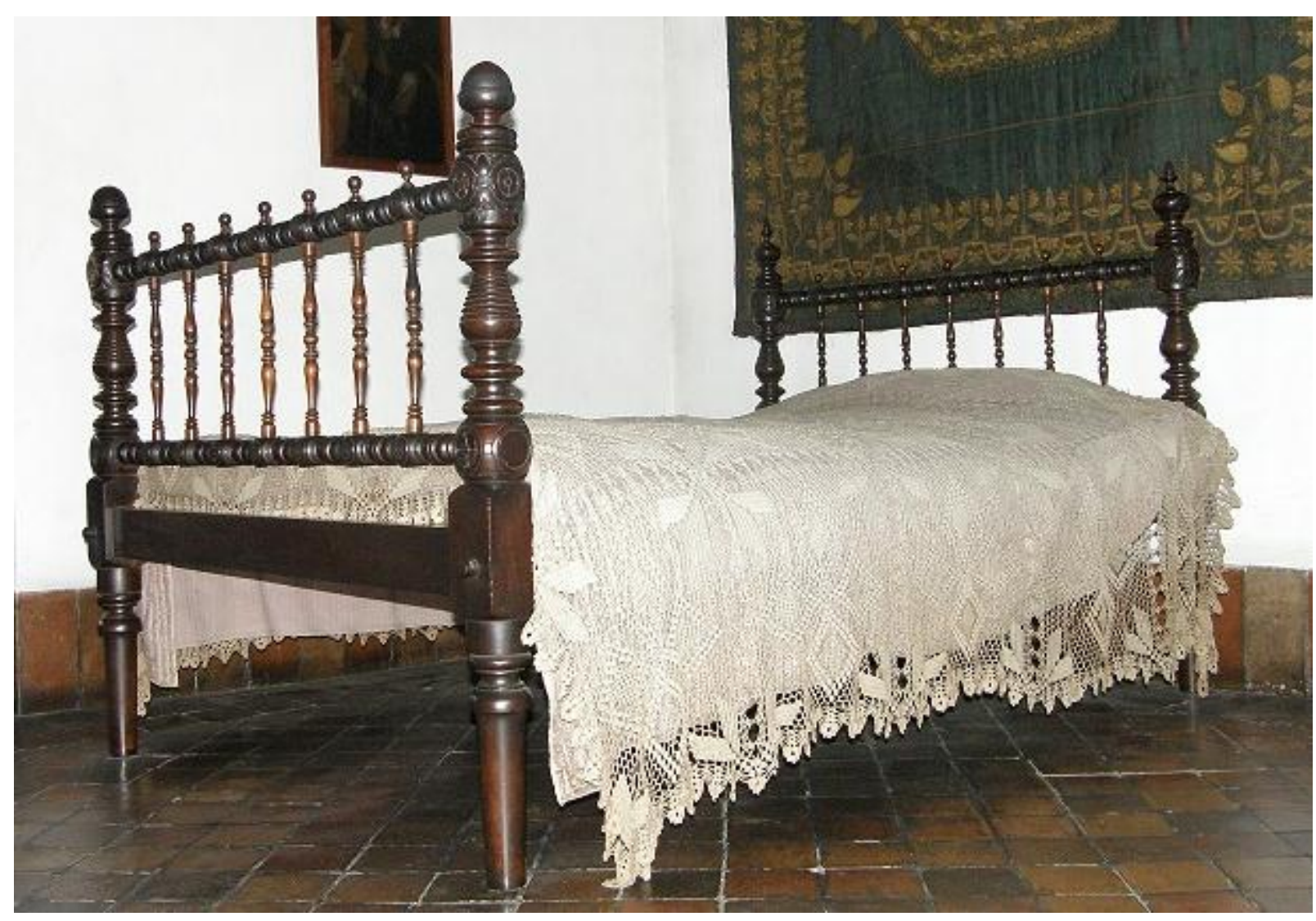

Fig.8. Cama torneada confeccionada con majagua y baría. Siglo XVII. Museo de Ambiente Histórico. Ciudad de Santiago de Cuba. 


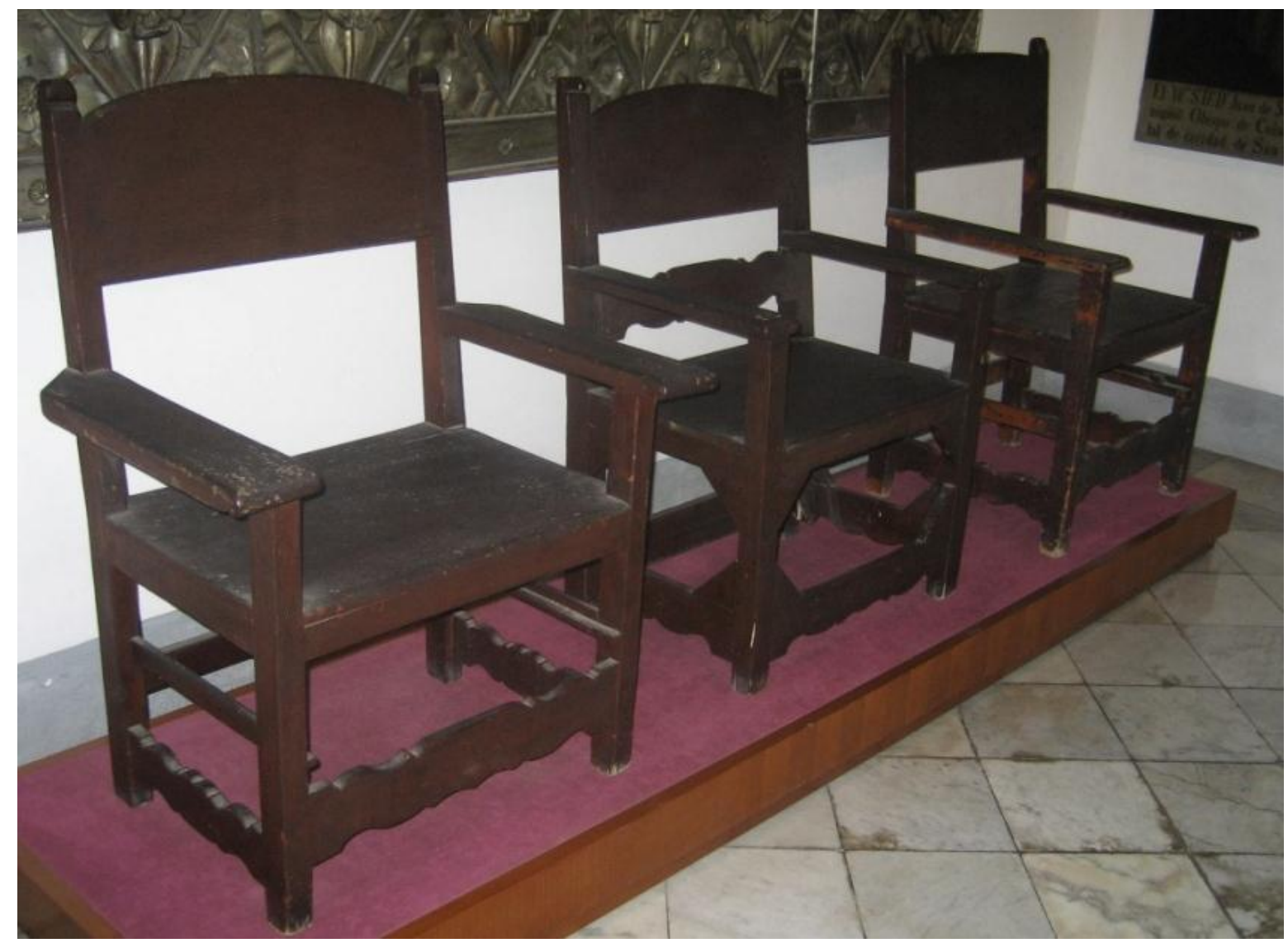

Fig. 9. Sillas de brazo o sillones "fraileros" de caoba. Museo de la ciudad. La Habana.

En algún momento del XVII, quizás a finales, su nombre debió ser indicador de poca jerarquía, y lo prestó a un mueble que tenía espaldar y llegó a ser y es muy común entre el campesinado cubano, que por lo general integraba las clases más humildes. Sillas y taburetes, debieron convivir en el mobiliario de aquellos más pudientes. En qué momento la silla de asiento y respaldo de cuero, perdió su nombre para convertirse en el clásico taburete cubano, se pierde en el tiempo. Los ejemplares conservados en algunos museos de Cuba y los datos que aparecen sobre ellos, no son suficientes para completar el estudio de su evolución, sin embargo, dejan constancia de su temprana presencia y sus características formales bien definidas, al punto de haber sido declarado como el "fósil" entre los muebles cubanos. ${ }^{39}$ (Fig.10)

Una cajonera o cómoda de sacristía como también se le conoce, Conformada por tres hileras gavetas superpuestas de hermosa talla de franca reminiscencia medieval, es ubicable en el plateresco español y es, si se quiere uno de los muebles más valiosos del XVII tardío en Cuba. Lo elaborado de su talla, plena de una enmarañada hojarasca de estirpe barroca, adorna su parte frontal a partir de sus seis gavetas, que poseen idéntica elaboración para cada una de sus tres hileras, en las que la superior es la más complicada, dado que además de diversos frutos que se confunden entre hojarascas, exhibe dos mascarones, uno a cada 
extremo de sus nueve cajones, elementos decorativos propios del barroco español. (Figs.11 y 12)

$\mathrm{Su}$ hermosa talla pudiera hacer pensar en un mueble importado, sin embargo, su escala, con casi cinco metros de ancho, la madera de cedro con que fue confeccionado, más la presencia en 1590 del Maestro Francisco Gutiérrez Navarrete maestro de ribera, del que afirmara el maestre de campo Juan de Texeda que "debe ser el mejor del mundo" 40 nos permite relacionar la temprana construcción de embarcaciones en Cuba con la fabricación de muebles de calidad como industria colateral, para uso de los más pudientes. La construcción naval en Cuba, continuó en los siglos posteriores, no sólo en La Habana, sino también en Bayamo. De ahí que la presencia de muebles de mayor complejidad, permite asociarlos a alguno de estos excelentes carpinteros, y de cierta forma explicar la prestancia de la talla de esta cajonera y otros exponentes confeccionados a lo largo del siglo siguiente.

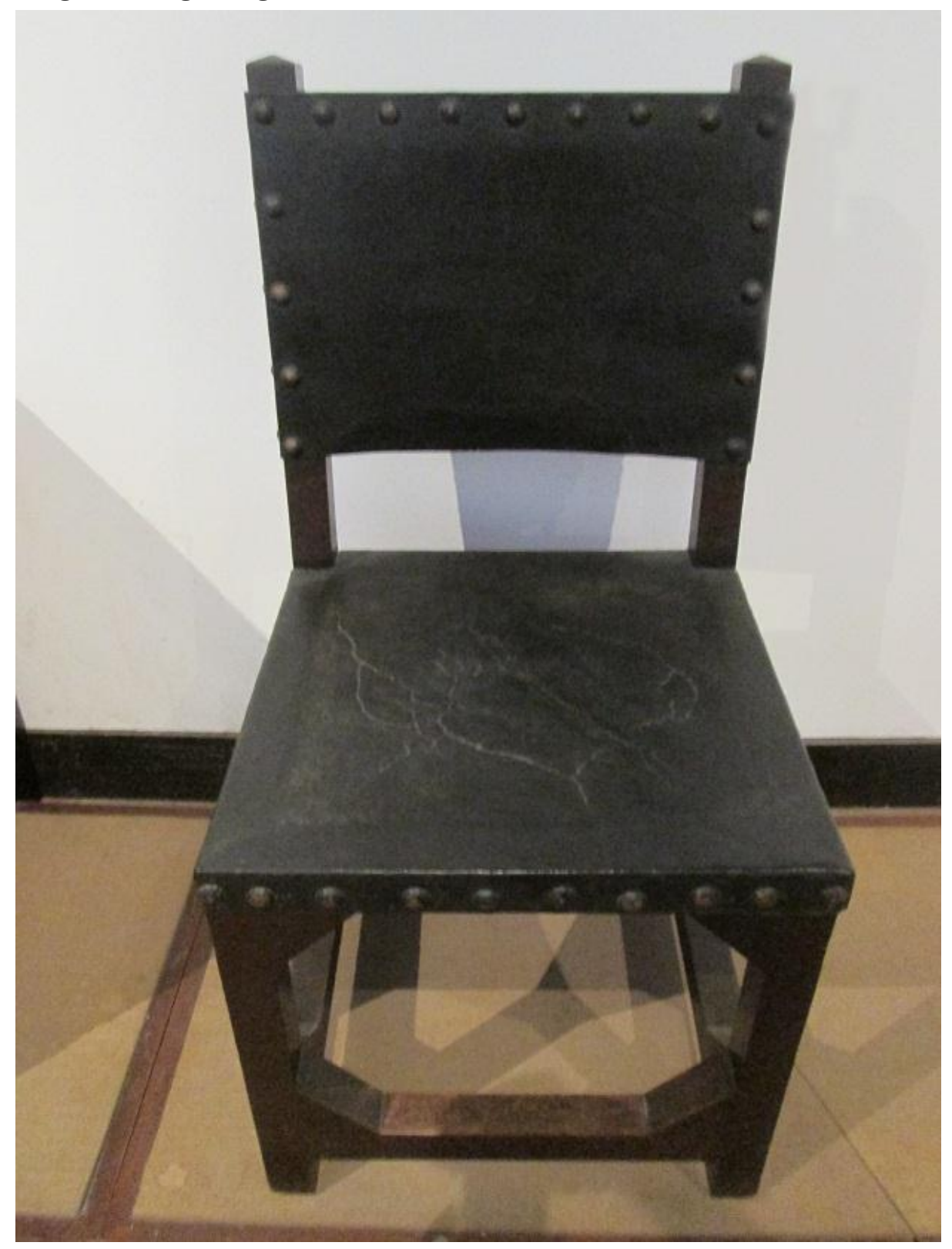

Fig.10 Taburete de caoba, baqueta y clavos de bronce. Siglo XVII. Museo de Arte Colonial de La Habana 

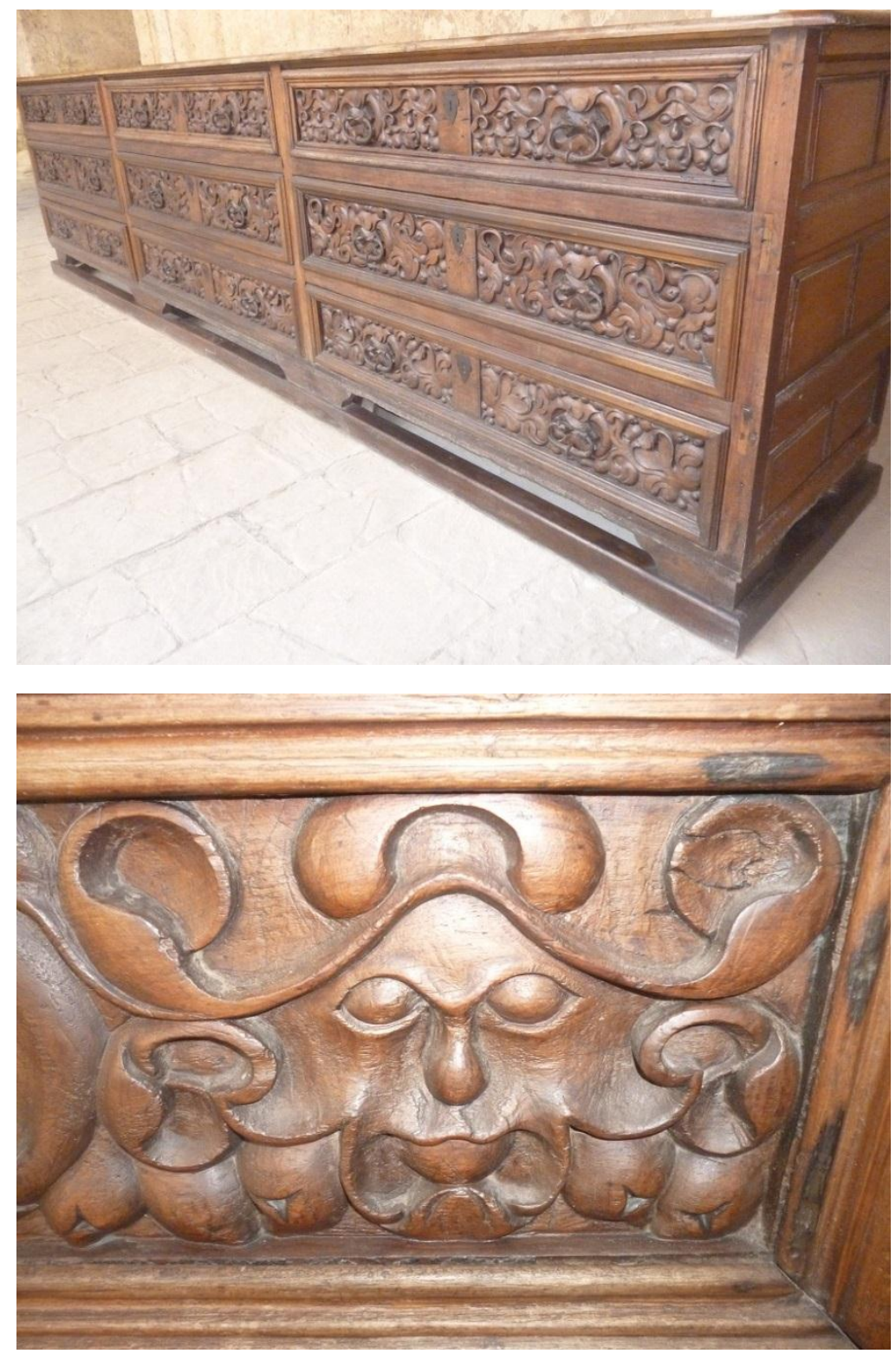

Fig. 11. Cajonera tallada, confeccionada en cedro. Fines del siglo XVII. Museo de Arte Religioso, Antiguo Convento de San Francisco. La Habana.
Fig.12. Detalle de la cajonera anterior.

La presencia de estos hombres en tierra cubana, conocedores de alto oficio, y la calidad de las maderas criollas, explica la gran valoración que ellas tuvieron en estos siglos entre los armadores de embarcaciones dentro y fuera de Cuba. Ambos elementos se unen y contribuyen a explicar una incógnita por años sin respuesta en cuanto al mueble cubano. ${ }^{41}$

En 1693 Inés de Jorge Monzón y Corté, deja en su testamento tres sillas "de vaqueta de la tierra bien tratadas", cuatro cuadros en lienzo de vara y media de largo, una cama de granadillo, un colchón. una mesa de cedro. Un "vufete de vaqueta de la tierra". Cuatro almohadas, dos acericos, una colcha azul de Campeche. Dos brazaletes de corales, una tagachuela de plata y una caja de cedro "con cerradura y llave". ${ }^{42}$ Además de la cama de granadillo, madera preciosa cubana, y los muebles de cedro, se mencionan sillas y un bufete todos confeccionados con "vaqueta de la tierra", es decir, cuero curtido en Cuba ${ }^{43}$, Este 
dato reafirma la suposición de la temprana confección de muebles en Cuba, con medios muy abundantes acá, como la madera y el cuero.

Otra cama de granadillo "con su colgadura de chorreado de china verde," más un escritorio "con su contador", una mesa de caoba y otras dos medianas, diez sillas usadas y cuatro taburetes, entre otros artículos son las aportaciones a un matrimonio ocurrido en $1696 .{ }^{44}$ Ambos conjuntos amplían un poco más acerca de la forma de vida de este siglo tan poco estudiado en Cuba y tan entrañable a medida que se avanza en su conocimiento.

Los resultados principales arrojan que en los siglos XVI y XVII pudieron realizarse en Cuba muebles de significativa calidad, algunos de relativo valor en cuanto a su talla, ello nos acerca a un mundo no tan simple, como el que hasta ahora se ha imaginado en cuanto a la cultura material cubana. A falta de nombres de pintores que aporten cierta luz acerca de la evolución de las artes plásticas, la ebanistería dejó una huella que permite un nuevo enfoque en el análisis de la sociedad de la época. Sus evidencias, causan natural asombro para aquellos que suponen un territorio evidentemente poco poblado, pero no tanto, ni de forma tan igualitaria a lo largo de dos siglos.

El incipiente desarrollo económico del primer siglo de la etapa colonial tuvo sus propias diferencias en la primera y segunda mitad del mismo. Igualmente los cambios paulatinos del siglo XVII, si bien lentos deben ser tenidos en cuenta si se quiere entender los progresos de la época. El estudio del mueble de estos años evidencia el desarrollo alcanzado como una parte muy importante de su cultura material .A partir del mueble cubano de estos años se puede conocer otra cara de la historia de Cuba hasta ahora poco tenida en cuenta.

Volver la mirada detenidamente hacia el desenvolvimiento de la incipiente industria naval que existe en Cuba desde el mismo siglo XVI y descubrir otros nombres de carpinteros de ribera, puede desentrañar el porqué de la fabricación de muebles cuya presencia en Cuba reclama otra lógica del proceso que permite colocar al mueble cubano en diferente posición con respecto a las producciones del mueble de América Latina. Dicha industria no sale de la nada, sino de una tradición que evolucionó, a través del desarrollo de un oficio que por su alto grado de anonimato, no permite ser esclarecida en su totalidad. Su valía evidenciada a partir de documentos y los ejemplares que se conservan del mobiliario cubano, particularmente del siglo XVII, constituye sin dudas un testimonio a tener en cuenta a la hora de un estudio profundo de la cultura material cubana y en especial de sus muebles.

\section{A manera de conclusiones:}

El estudio del mueble de los siglos XVI y XVII en Cuba permite apreciar con cierta coherencia nuevas valoraciones acerca de su cultura material muy poco apreciada hasta la actualidad. La investigación sistemática y profunda de sus materiales, técnicas, estilo o tipología y grado de conservación, puede ofrecer otras posibilidades en cuanto a su valor y significado. Un análisis pormenorizado 
del desarrollo del mueble en Cuba constituye obligado reto si se pretende comprender mucho más ciertas páginas de su historia del arte, de su cultura y por tanto de su historia. Sirvan estas apreciaciones para desbrozar el camino.

\title{
NOTAS
}

\begin{abstract}
${ }^{1}$ Encabeza la lista de los estudiosos: ARROYO, Anita con el epígrafe III titulado "El Mueble" dentro del capítulo IV dedicado a "La Madera" en su libro Las Artes Industriales en Cuba. Editado por Cultural S.A., La Habana, 1943. Le sigue Museo Colonial, Santiago de Cuba, Editorial Oriente, Santiago de Cuba,1978 con introducción y un epígrafe titulado Casa museo de ambiente Colonial que sin ser firmados, puede afirmarse que son de la autoría de PRAT PUIG, Francisco .Otros autores que deben ser tenidos en cuenta son los publicados en la colección Museos y Monumentos, entre los que se deben mencionar Museo de ambiente histórico cubano, de RÍOS MARRERO, Lucía Nery, Editorial Oriente, Santiago de Cuba,1984, MÉNDEZ PLASENCIA, Miriam y Margarita Suárez García, Museo de Arte Colonial, Editorial, Letras Cubanas, Ciudad de La Habana, Cuba,1985. OTERO DE ARMAS, Elena. El Juego de sala en la Cuba republicana, Editorial gente Nueva, La Habana, 1985. SUÁREZGARCÍA, Margarita y Severino Rodríguez Valdés con su artículo Alas de caoba, en Opus Habana, V. II, No. 1, 1998, pp.40-49. De RODRÍGUEZ CORRALES, Lázaro "Apuntes sobre el mueble en Cuba: Su evolución en la Colonia y en la República”. Revista Vitral, No. 45, año VIII, septiembre-octubre, 2001.pp. 4049. Así como de CONNORS, Michael En torno al mueble colonial cubano en Opus Habana, Vol. VI, No. 3, 2002, pp. 26-35.Del mismo autor Cómodas de sacristía: un acercamiento al mueble colonial cubano en Opus Habana, Vol. VIII, No. 2, 2004, pp. 22-31 y Cuban Elegance, Harry N. Abrams, Inc., Publishers, New York,
\end{abstract} 2004.

${ }^{2}$ SANTOS, Elsa. El mueble cubano y su notable belleza. Entrevista realizada a Francisco Prat Puig en Sierra Maestra, Santiago de Cuba, 25 de agosto de 1985,p 4.El profesor Prat dejó inaugurado un Museo de Ambiente Histórico en 1970en Santiago de Cuba, primero de su tipo en el país y paradigmático en cuanto al tratamiento del mueble cubano.

${ }^{3}$ Uno de los primeros estudiosos de la cultura cubana en utilizar el término de Cultura Material fue el arqueólogo, investigador y profesor Francisco Prat Puig. De origen catalán, fue profesor de la Universidad de Oriente, Cuba, por más demedio siglo. Fue galardonado con las siguientes distinciones;" 50 años dela Educación, Orden de la Alfabetización, De la Cultura Nacional, Laureado de la Cultura Frank País, Orden Alejo Carpentier y la Orden Félix Varela. En 1992, el Estado Español le concedió la Orden 'Isabel la Católica”'. Véase. PRAT PUIG, F. El Pre Barroco en Cuba. Una Escuela Criolla de Arquitectura Morisca, Fundació Caixa Manresa, Diputació de Barcelona. S/F, p. X.

${ }^{4}$ El Mundo de las antigüedades. El Mueble de los siglos XV y XVI. España, Portugal y otros Países, PlanetaAgostini, Barcelona, 1989, pp., 36-41.

${ }^{5}$ LUCIE-SMITH, Edward, Breve Historia del Mueble, Ediciones Destino Thames and Hudson, Barcelona, 1998, pp. 53-68.

${ }^{6}$ LOZOYA, Marqués de, Muebles de Estilo Español, desde el Gótico hasta el siglo XIX, Editorial Gustavo Gili S.A., Barcelona, 1962, p 20.

${ }^{7}$ Como la mayoría de los sillones o sillas de brazo conservadas en Cuba, provienen de iglesias y conventos, son denominados "fraileros", tal y como sucedía en España en dicho siglo. "El de más permanente arraigo -en la vida española es el sillón de brazos que solemos llamar 'frailero', sin duda porque su decorosa austeridad, no incompatible con una perfecta adaptación al cuerpo humano hizo de él el mueble preferido de las celdas monásticas," LOZOYA, Marqués de, op. cit, pp. 20-21.

${ }^{8}$ En Cuba se les denomina así pero "El de bargueño es nombre reciente y en realidad carente de sentido histórico, pues sólo se emplea de forma generalizada desde 1872, aludiendo erróneamente a dos hipotéticos orígenes de la tipología: al toledano pueblo de Bargas y a un supuesto 'ebanista' toledano de igual apellido". El Mundo de las antigüedades. El Mueble de los siglos XV y XVI (...).Ob. Cit., p 46.

${ }^{9}$ El Mundo de las antigüedades. El Mueble de los siglos Ob. cit., p.26.

${ }^{10}$ PRAT PUIG, Francisco, Museo Colonial, Santiago de Cuba. Editorial Oriente, Santiago de Cuba, 1978. p. 9 
${ }^{11}$ Documentos Inéditos. Relativos al Descubrimiento, Conquista y Organización de las antiguas Posesiones Españolas de Ultramar. Segunda Serie. T.1, De la Isla de Cuba. Publicada por la Real Academia de la Historia. Est. Tipográfico "Sucesores de Rivadeneira", Madrid, 1885, p.70.

12 Ibídem, p.169.

${ }^{13}$ Ibídem, p. 174.

${ }^{14}$ DE LATORRE, José María, Lo que fuimos y lo que somos o la Habana antigua y moderna, Imprenta de Spencer y Compañía, 1857, XIV, s/p.

15 TRELLES, Carlos M., Ensayo de Bibliografía Cubana de los siglos XVII y XVIII. Seguido de unos Apuntes para la Bibliografía Dominicana y Portorriqueña, Imprenta El Escritorio, Matanzas, s/p, 1907, pp. $224-226$. ${ }^{16}$ Ibíd.

${ }^{17}$ Estas ordenanzas fueron conocidas así, porque fue el doctor Alonso de Cáceres quien llegado a Cuba en 1573 se encargó de organizar los consejos municipales, los cuales funcionaban hasta esa fecha sin leyes ni ordenanzas, por tal motivo adaptó para ellos las Ordenanzas de Felipe II.

18 FRANCO, José Luciano, Apuntes para una Historia de la legislación y administración colonial en Cuba 1511-1800, Editorial de Ciencias Sociales, La Habana, 1985, p. 185.

${ }^{19}$ MARRERO, Leví, Cuba: Economía y Sociedad, Siglo XVI: la economía, Editorial Playor, S.A., Madrid, 1974, p.174.

${ }^{20}$ La mayoría de las arcas que se conservan en Cuba provienen del antiguo Convento de Santa Clara, fundado en La Habana en 1640. Ellas debieron formar parte del patrimonio que traían consigo las monjas, que pudo pertenecer a una época anterior.

${ }^{21}$ DE ROJAS, Marta. Ob. cit. pp. 8-9.

${ }^{22}$ Según Marta de Rojas, que cita el Diccionario de Autoridades, como cama se consideraban a veces las colgaduras "compuestas de cortinas, cenefa y cielo", mientras que red "es una labor que hazen las mujeres de hilo, para colgaduras y otras cosas”. DE ROJAS, Marta. Ob.cit. p. 378.

${ }^{23}$ La mesa de cadena y goznes "a la moda de España” era aquella que subía o bajaba su tablero, según se necesitara. Los goznes servían para trabar el perno que aseguraba la cadena.

${ }^{24}$ CURIEL, Gustavo, “Ajuares Domésticos. Los Rituales de lo Cotidiano", Historia de la Vida Cotidiana en México. La Ciudad Barroca, Tomo II, Colegio de México- Editorial Fondo de Cultura Económica, México, 2005. pp. 83-85.

${ }^{25}$ LOZOYA, Marqués de y José Claret Rubira Arq. Ob. cit., p.123.

${ }^{26}$ Otro dato que da fe del linaje de esta dama, es el permiso que recibe otra para sentarse a su lado en la iglesia. Luisa Farfán entregó 25 ducados al convento de San Juan de Letrán, por lo que los monjes dieron tal autorización y le conceden un asiento en la iglesia de dicho convento, junto al que María Recia posee junto al altar de nuestro Señor, "para que doña Luysa (sic) se pueda asentar en él todos los días de su vida y que goze (sic) de dicho asiento sin que ninguna persona se lo pueda estorbar.DE ROJAS, Marta. Ob. cit. pp., 204-205.

${ }^{27}$ Connor compara estos arcones con los de Bermudas y reconoce en ellas influencias morisco-españolas. CONNOR Michael. En torno al mueble colonial cubano. Ob.cit.p.29.Pero no todos los arcones cubanos están confeccionadas en cola de milano como él afirma. Sin embargo, sus "uniones intrincadas" pueden reconocerse como machihembradas y también empalmadas en forma de cola de pescado.

${ }^{28}$ LORENZO MONTERRUBIO, Carmen, Arte Suntuario en los Ajuares Domésticos. La dote matrimonial en Pachuca, Siglo XVII, Universidad Autónoma del Estado de Hidalgo, Pachuca de Soto, Hidalgo, México, 2015, p 91.

${ }^{29}$ MARRERO, Levi. Ob. cit., p 456.

${ }^{30}$ La costumbre de usar estas cajas de madera para guardar granos y semillas y otros tipos de alimento de cierta duración como la harina se conservó en algunas casas de campo cubanas hasta bien avanzado el siglo XX.

${ }^{31}$ En 1590 Francisco de Moncayo era copropietario de la Isla de Pinos, actual Isla de la Juventud, junto al acaudalado Hernán Manrique de Rojas. MARRERO, Leví. Ob.cit.p104.Un coetáneo comenta en 1598:"Los pobladores acomodados mandan a Castilla el ébano y el granadillo, maderas preciosas que aquí abundan, y de allí le vienen construidos ricosdormitorios que llaman camas imperiales”. DE LA TORRE, José María. Ob. cit. $\mathrm{s} / \mathrm{p}$

${ }^{32}$ MARRERO, Leví. Ob. cit. p, 456. 
${ }^{33}$ Dicha silla pertenece a la colección del profesor Francisco Prat Puig.

${ }^{34}$ Este escritorio se encuentra en la Dirección de Patrimonio Cultural de la provincia de Cienfuegos.

${ }^{35}$ MARRERO, Leví, Cuba. Isla Abierta. Poblamiento y Apellidos. (Siglos XVI-XIX), Ediciones Capiro, Puerto Rico, 1995, p 29.

${ }^{36}$ El Mundo de las antigüedades...Ob.cit.p.26.

${ }^{37}$ Esta cajonera escritorio se exhibe en el Museo de Arte Religioso en el Antiguo Convento de San Francisco, La Habana. Allí está clasificado como del Siglo XIX.

${ }^{38}$ RÍOS MARRERO, Lucía N., Museo de Ambiente Histórico Cubano, Editorial Oriente, Santiago de Cuba, 1984, p. 51.

${ }^{39}$ Museo de arte colonial, Editorial Oriente, Santiago de Cuba, 1978, p. 10.

${ }^{40}$ Téngase en cuenta que en 1591, Felipe II autorizó a Juan de Texeda a dejar 42 carpinteros tomados de la flotas para la urgente tarea de confeccionar fragatas en el puerto de La Habana. MARRERO, Leví. Ob. cit. t. II, p. 203.

${ }^{41}$ En 1588 vivían en la Habana los siguientes carpinteros de ribera: Bartolomé Rodríguez, Antón Rodríguez, Juan Roque, Domingo González y Hernando del Castillo. DE ROJAS, Martha. Ob. cit. pp. 56,167 y 208.

${ }^{42}$ DE SALINAS, Antonio, Protocolos. Archivo Nacional de Cuba Testamento de Inés de Jorge Monzón y Cortes, viuda de Hernández Portal, Escritura de 25 de abril de 1693, s/f.

${ }^{43}$ La técnica del curtir el cuero era común en La Habana desde el siglo XVI. "Tenemos noticias de varias plantas de curtir el cuero o tenerías en La Habana antes de terminar el siglo". MARRERO, Leví. Ob. cit. t. 2, p. 102

${ }^{44}$ OZETA, URIBE, Protocolos. Archivo Nacional de Cuba. Aportación al matrimonio de Pedro de Villa Hernández y Sabina Suárez del Portal Escritura de 30 de abril de 1696, s/f. 